\title{
Handbook of Research on 5G Networks and Advancements in Computing, Electronics, and Electrical Engineering
}

Part of the Advances in Computer and Electrical Engineering Book Series

Augustine O. Nwajana (University of Greenwich, UK) and Isibor Kennedy Ihianle (Nottingham Trent University, UK)

\section{Description:}

The advent of the emerging fifth generation (5G) networks has changed the paradigm of how computing, electronics, and electrical (CEE) systems are interconnected. CEE devices and systems, with the help of the 5G

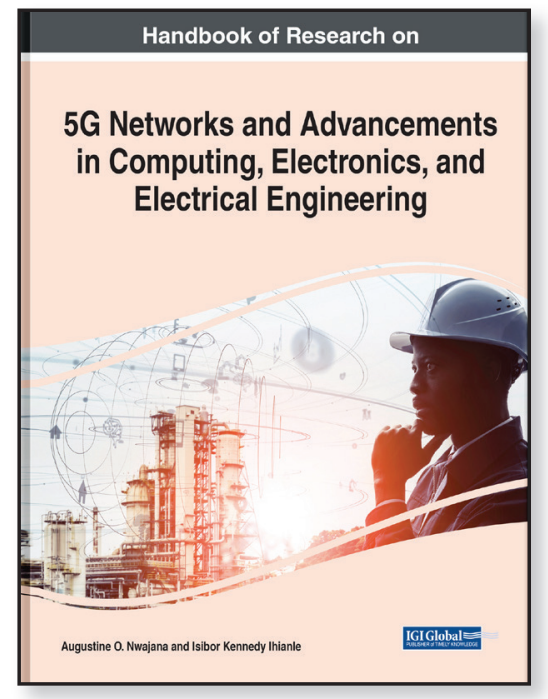
technology, can now be seamlessly linked in a way that is rapidly turning the globe into a digital world. Smart cities and internet of things have come to stay but not without some challenges, which must be discussed.

The Handbook of Research on 5G Networks and Advancements in Computing, Electronics, and Electrical Engineering focuses on current technological innovations as the world rapidly heads towards becoming a global smart city. It covers important topics such as power systems, electrical engineering, mobile communications, network, security, and more. This book examines vast types of technologies and their roles in society with a focus on how each works, the impacts it has, and the future for developing a global smart city. This book is ideal for both industrial and academic researchers, scientists, engineers, educators, practitioners, developers, policymakers, scholars, and students interested in 5G technology and the future of engineering, computing, and technology in human society.

$\begin{array}{llll}\text { ISBN: } 9781799869924 & \text { Pages: } 400 & \begin{array}{l}\text { Copyright: } 2021 \\ \text { Hardcover }+\end{array} & \text { Release Date: June, } 2021 \\ \text { Hardcover: } \$ 295.00 & \text { E-Book: } \$ 295.00 & \begin{array}{l}\text { E-Book: } \$ 355.00 \\ \end{array} & \end{array}$

\section{Topics Covered:}

$5 \mathrm{G}$ Networks

Antennas

Artificial Intelligence

Computing

Electrical Engineering

Energy Engineering
Mobile Communications

Nanoelectronics

Network and Cyber Security

Smart Societies

Unmanned Aerial Vehicles (UAVs)

\section{Subject: Science and Engineering \\ Readership Level: Advanced-Academic Level (Research Recommended)}

Classification: Handbook of Research

Research Suitable for: Advanced Undergraduate Students; Graduate Students; Researchers; Academicians; Professionals; Practitioners 